\title{
Meconium peritonitis
}

\begin{abstract}
Meconium peritonitis is a rare prenatal disease with an increased rate of morbidity and mortality. Establishing clear prenatal diagnosis obtained by ultrasound Prenatal and postnatal ultrasound may be present: abdominal calcifications, ascites, polyhydramnios, meconium pseudocyst, echogenic mass and dilated bowel or intestinal obstruction. Clinical results are different depending on the presence of antenatal diagnosis of meconium peritonitis and its form, which can be mild or severe. One of the treatment and management of meconium peritonitis depend on the clinical presentation of the newborn. Meconium peritonitis diagnosed prenatally differs from that of the newborn, not only concerning the mortality rates but also through reduced morbidity and overall better prognosis.
\end{abstract}

Volume 5 Issue 2 - 2019

\section{Sanjaya INH, Florencia Desiree \\ Department of Obstetrics and Gynecology, Fetomaternal \\ Division, University Hospital Sanglah, Indonesia}

Correspondence: Sanjaya INH, Department of Obstetrics and Gynecology, Fetomaternal Division, University Hospital Sanglah, Bali, Indonesia, Email florenciadesiree88@gmail.com

Received: January 24, 2018 | Published: April 02, 2019

Keywords: meconium peritonitis, fetal ascites, bowel ateresia, bowel perforation, intraabdominal calsification, fetal sonography

\section{Introduction}

Meconium peritonitis is a steril chemical peritonitis usually resulting from antenatal bowel repture. Meconium peritonitis is a rare prenatal disease with an increased rate of morbidity and mortality in the neonatal period. Neonatal studies suggest a prevalence of 1 in 35,000 live births. ${ }^{1}$ Meconium peritonitis (MP) can be diagnosed if a hyperecogenic area is found in the stomach of the fetus in the second and third trimesters of pregnancy. The etiology of MP is hought to be the result of a sterile chemical reaction resulting from bowel (ileum) perforation in utero. There is usually an intense inflammation from meconium peritonitis, which may incite calcification along the surface of bowel or peritoneum. In time the inflammatory response may seal the perforation or alternatively may form a pseudocyst or wall of meconium. This pseudocyst has a thin and often calcified wall. The other respons of inflamatory response are ascites and fibrosis. The end result of this process is three types of meconium peritonitis: fibroadhesif, cystic, diffuse and healing.

\section{Case report}

Mrs. S, a 35 year old multigravida, was referred at 24-25 weeks of gestation with hydrops fetalis for further investigation. Her last menstrual period was 09-09-2006. She complained about her stomach is larger than the previous pregnancy and feels tense. Previous history of her first pregnancy wasdelivered by sectio caesarea due to antepartum bleeding due to placenta previa. Blood Type $\mathrm{B}, \mathrm{Rh}$ positive. $^{2-5}$

A antenatal ultrasound examination showed a male fetus, single turn life, transverse presentation, with ascites and echogenic bowel and polyhydramnion. There is no other anatomical anormalities. The baby fetometry: BPD:6,62cm (25weeks+3days); AC: $25,93 \mathrm{~m}$ (30weeks +1 day); FL:3,74cm (21weeks+6days) average: 26 weeks + 3days; EFW: 1224gram. Placental located posteriorly with a thickness of $3.99 \mathrm{~cm}$ in the central area. Doppler examination of umbilical artery S/D ratio: 3.24 with Pulsatil index: 1.16. And PSV (peak systolic velocity) in MCA (middle cerebral artery) $27,9 \mathrm{~cm} / \mathrm{sec}$ $(<1,5 \mathrm{MoM})$ which means normal (no anemia in fetus). Serological examination TORCH (Toxoplasmosis Ig G (+), IgM (-); IgG (+), IgM (-) Cytomegalovirus IgG (-); Herpes virus 1 Ig G(-), Ig M(-) (Figures $1-3)$.

In this case amniocentesis is performed for karyotyping examination with $46 \mathrm{XY}$ chromosome as the results. In this patient, amnion reduction was performed in serial because of polyhidramnion, and parasentesis because there was a massive ascites in the fetus that can cause pressure on the diaphragm. Examined bacterial culture on paracentesis fluid. Obtained a sterile results. At the age of pregnancy above 34 weeks there is a reduction in the amount of ascitic fluid and the amnion volume to normal. As shown in Figure 4.

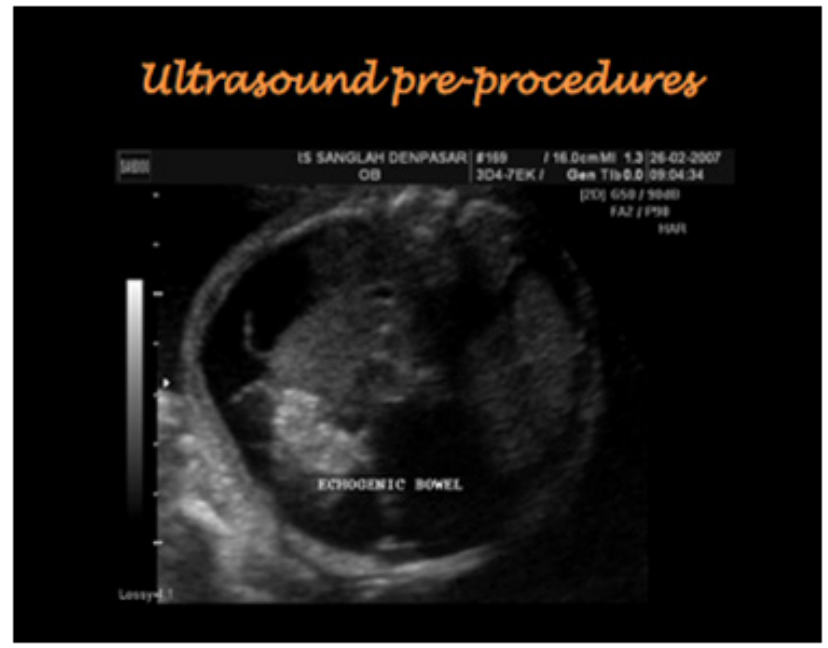

Figure I 24 weeks 2 days. Ascites with echogenic bowel.

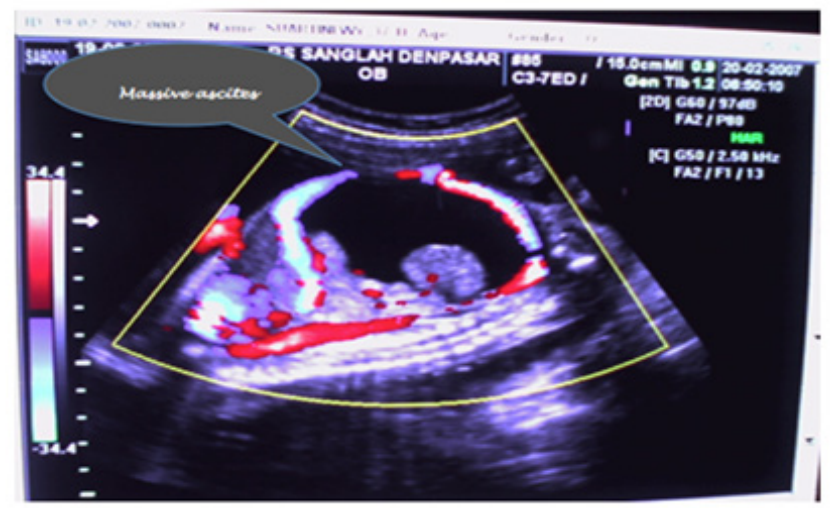

Figure 224 weeks 2 days. There is ascites ( colour dopler- mid sagital section).

Furthermore, weekly serial monitoring with ultrasound was performed. Spontaneous labor during 40-41 weeks' gestation, is 
performed by vacuum extraction because the patient is not effectively straining. Born baby boy, 3300grams, birth length: $52 \mathrm{~cm}$, head circumference: $35 \mathrm{~cm}$, chest circumference: $34 \mathrm{~cm}$, abdominal circumference: $33 \mathrm{~cm}$, fit, APGAR score: $1^{\prime}: 8$ and 5':10. Hemoglobin: 16.9 gram $\%$, albumin: $4 \mathrm{gram} \%$. Micturition is normal, defecation normal, breastfeeding well.

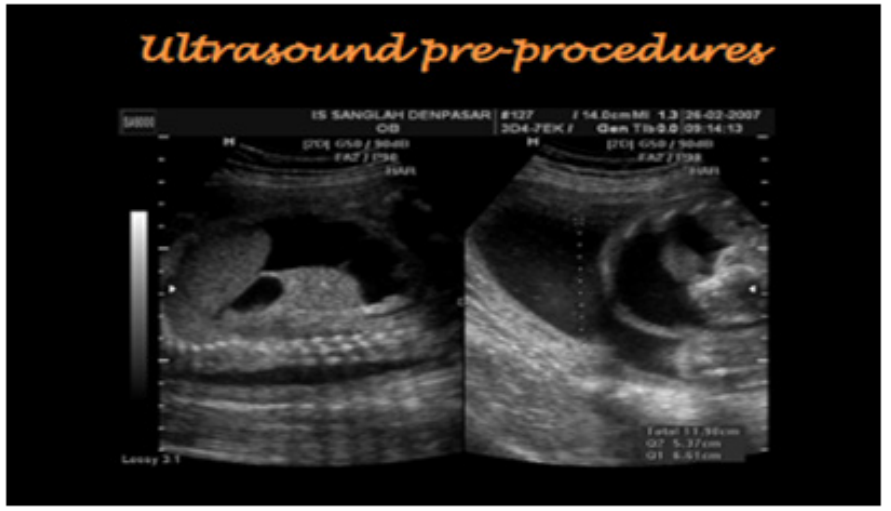

Figure 324 weeks 2 days. Polyhidramnion.

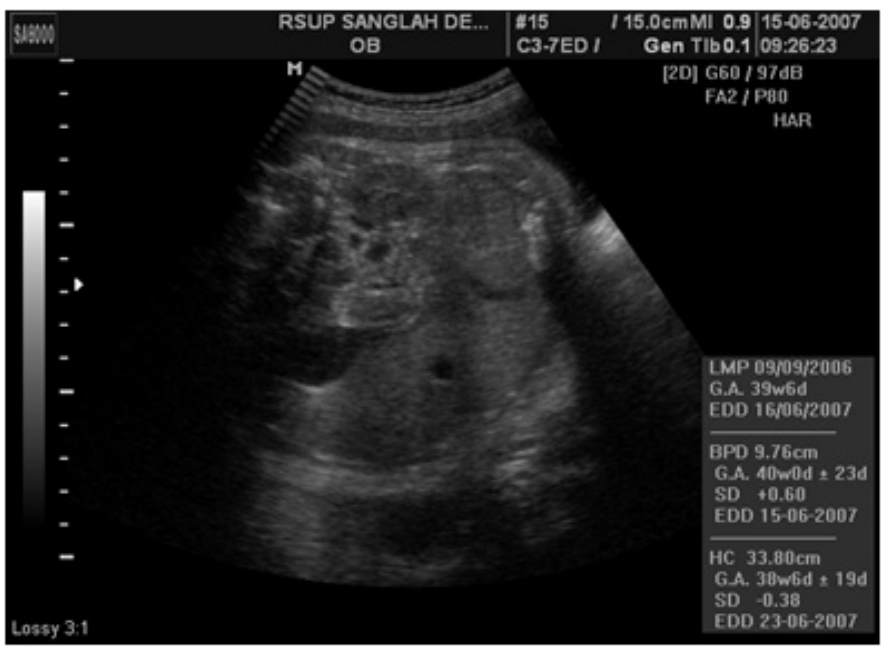

Figure 439 weeks 6 days, liver USG, no ascites.

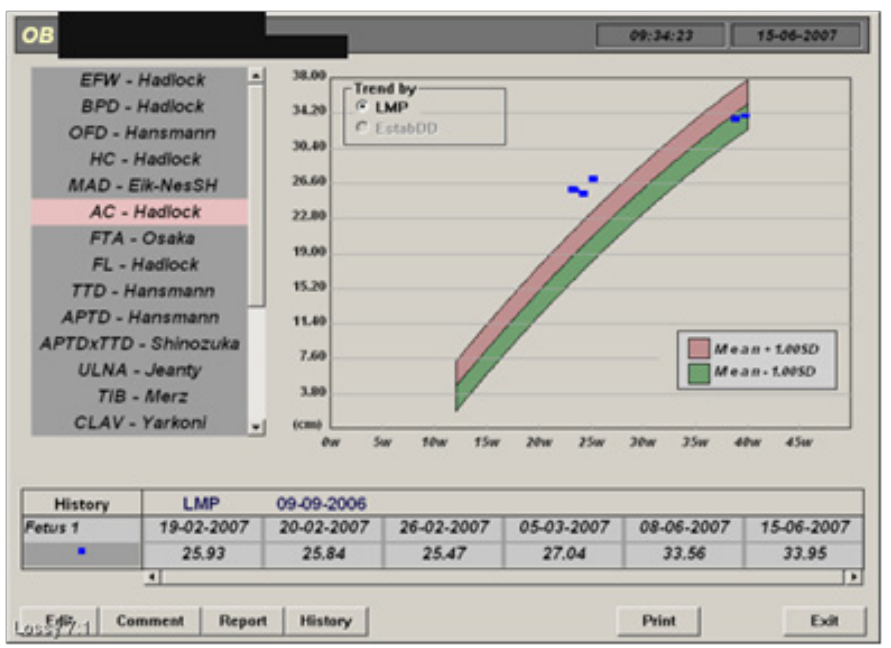

Figure 5 Abdominal circumference.
The baby performed X-ray abdomen, visible an air filling the upper intestine to the lower intestine. A CT scan was performed to look for signs of calcification in the cerebrumrelated to cytomegalovirus infection. No intra-cranial calcification was found, there was a presence of hyperdene mass in occipital, sulcus and gyrus cerebri was normal. The evaluation from the Neurosurgeon is concluded taht there is an intracranial hemorrage in occipital region and treated conservatively. The final state of the fetus until the time of this report is made is in a good condition (Figures $6 \& 7$ ).

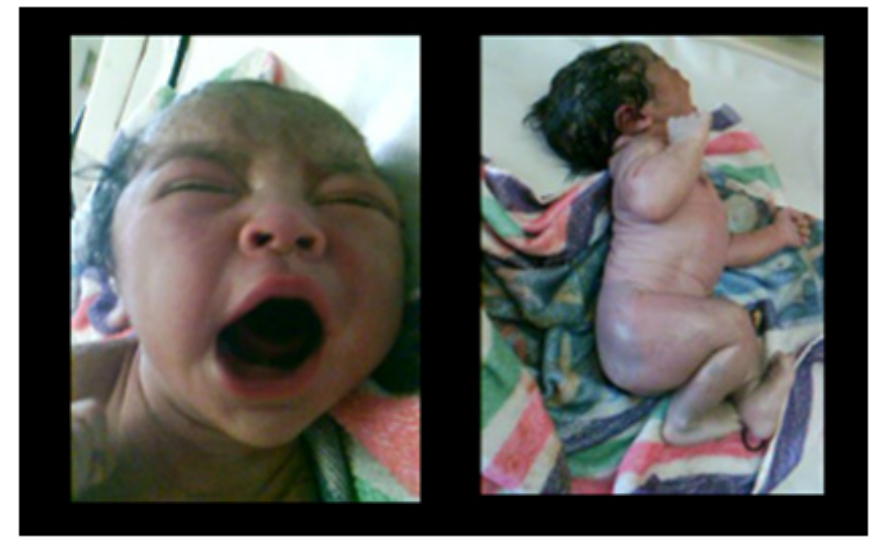

Figure 6 shortly after birth.

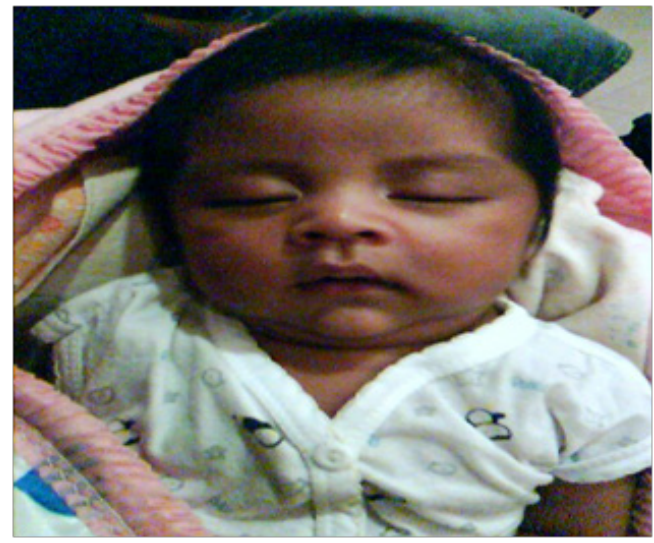

Figure 720 days.

\section{Discussion}

Meconium peritonitis is defined as a localized or generalized peritonitis,aseptic, chemical or foreign body, due to leakage of meconium into the peritoneal cavity correlated with antenatal perforation of the digestive tract. The syndrome was first described by Morgagni in 1761, and the first surgical correction was performed successfully in 1943, by Agerty. ${ }^{5}$ It can have a wide range of presentations and is classified into 3 types as follows: generalized, cystic, and fibroadhesive types. ${ }^{6}$

Antenatal diagnosis should include testing for congenital anatomical or structural abnormalities, cystic fibrosis, chromosomal abnormalities, chemical and histological analysis of fetal peritoneal fluid obtained by paracentesis. ${ }^{7}$ An animal experimental studies show that new calcifications are detected after 8 days from meconium out into the peritoneal cavity. The most common cause of meconium peritonitis is an ischemic lesion of the ileum associated with 
mechanical obstruction (atresia, volvulus, intussuception, congenital bands, Meckel diverticulum and interna hernia). This cause occurs in $50 \%$ of cases of meconium peritonitis. Meconium peritonitis can also be caused by cystic fibrosis. Meconium ileus due ti cystic fibrosis has been identified in $15 \%-40 \%$ of infants with meconium peritonitis. a viral infection (cytomegalovirus or parvovirus B19). Meconium ileus is also a cause in less than $25 \%$ of cases of meconium peritonitis. ${ }^{1,4}$

Prenatal sonography can support the diagnosis of meconium peritonitis, an intra-abdominal calcification, ascites, polyhydramnios and bowel dilatation. Foster et al reported incidence of sonographic features of seven cases of meconium peritonitis: intra-abdominal calcification was found in $86 \%$, ascites at $64 \%$, polyhydramnios at $71 \%$ and $46 \%$ bowel obstruction. There are three main types of meconium peritonitis that can be identified on prenatal ultrasound: cystic (meconium pseudocyst), diffuse, and fibrosadhesive examinations. ${ }^{1}$

Meconium pseudocyst is the most common image of sonography in meconium peritonitis and the appearance of hyperechoic mass. Ascites are also commonly found. Diffuse meconium peritonitis is usually associated with polyhydramnios, fetal ascites and a number of intra-abdominal calcifications. The fetal abdominal wall may also appear to be thickened by edema. This type of fibroadhesive meconium peritonitis results from the presence of numerous calcium deposits in the peritoneum that can close the lesions of the intestine. ${ }^{1,3}$ Additionally, the presence of intestinal pseudocysts and isolated polyhydramnios are almost pathognomonic sign. ${ }^{7-9}$

In this case the ascites begin to decrease spontaneously at 34 weeks' gestation. Whether this is related to the maturity of the gastrointestinal tract. As the ascites diminished, the amnionic fluid volume becomes normal. Does paracentesis in the fetus (fetal abdominocentesis) provide benefits to improve the prognosis in this case? And ascites in the fetus will disappear spontaneously without intervention? The question needs to be discussed.
In this case examination for detection of parthyroid B19 cannot be done because it can not be done in Indonesia.

\section{Acknowledgments}

None.

\section{Conflicts of interest}

The author declares there are no conflicts of interest.

\section{References}

1. http://www.fetalsono.com/Demo/DemoAns.html

2. Douglas zS Richards, Mark Preziosi, Carol Sexton. Cytomegalovirus syndrome with ascites, hepatitis, and negative serology.

3. Boris Petrikovsky, Kenneth Kenigsberg, Beth Pletcher. Meconium peritonitis mimicking urinary ascites.

4. Woodward, Kennedy Sohaey. Obstetrics top 100 diagnoses.1st ed, AMIRSYS,Utah, 2003. p. 152-154.

5. Kang B. P22.08: Meconium peritonitis: prenatal diagnosis and postnatal outcome. Ultrasound in Obstetrics \& Gynecology. 2009. p. 264-65.

6. Uchida K, Koike Y, Matsushita K, et al. Meconium peritonitis: Prenatal diagnosis of a rare entity and postnatal management. Intractable Rare Dis Res. 2015;4(2):93-97.

7. Wang CN, Chang SD, Chao AS, et al. Meconiumperitonitis in uterothe value of prenatal diagnosis in determining neonatal outcomes. Taiwanese J Obstet Gynecol. 2008;47(4):391e6.

8. Kitamura RK, Midulla P, Mirensky T. Meconium peritonitis following intestinal atresia: A case report. Journal of Pediatric Surgery Case Reports. 2016;9:9-10.

9. Dirkes $\mathrm{K}$, Crombleholme $\mathrm{T}$, Craigo $\mathrm{S}$, et al. The natural history of meconium peritonitis diagnosed in utero. $J$ Pediatr Surg. 1995;30(7):979e82. 